\title{
TALO-CALCANEAL BRIDGING IN AN ANGLO-SAXON
}

\author{
by \\ JOHN* AND ANGELA CALDER
}

\section{SUMMARY}

A RECENTLY excavated skeleton from an Anglo-Saxon burial ground in Kent exhibits a pathological right heel. The disorder is identified as a congenital talo-calcaneal bridge, a genetic anomaly which often results in "peroneal spastic flat foot". This 1,300 -year-old specimen is presently the oldest reported for this disorder.

\section{SITE LOCATION AND DESCRIPTION}

An Anglo-Saxon cemetery at Updown in Kent, consisting of over 300 graves, ${ }^{1}$ was this year partially threatened by construction work. A rescue excavation of thirty-six graves threatened by this development, was undertaken.

This 1,300-year-old site ${ }^{2}$ is situated some 11.5 kilometres north-west of Dover on a prominent chalk hill beside the Roman road which runs from Dover to Richborough. The graves were orientated on an east-west axis and were well dug into the chalk substrata. The stratigraphy of each burial was relatively uncomplicated but several were disturbed by tree roots, or rodent activities. These factors, together with the permeable nature of the chalk, ensured that any surviving skeletal remains were extremely fragmentary.

The profile of the population exhumed included sixteen males, thirteen females, and seven individuals of unknown sex. ${ }^{3}$ All age groups from infancy to post forty-five years were represented, and stature estimates were comparable to those from other nearby Anglo-Saxon populations.,5

\section{GENERAL PATHOLOGY}

Most of the pathology detected, such as hypoplasia, dental attrition, and vetebral osteoarthrosis, was typical for this period. ${ }^{6,7,8}$ However, Grave 12 produced the

*John Calder, M.B., ChB., Department of Orthopaedics, Royal Adelaide Hospital, South Australia.

1 J. K. St. Joseph, ‘Air reconnaissance: recent results 35’, Antiquity, 1974, 48: 213-215.

${ }^{2}$ Mrs. S. E. C. Hawkes, personal communication.

3 Angela Calder, 'Bone report, Updown excavation, 1976', in preparation.

4 S. Jarman, 'Preliminary Report on the Skeletal Material from the Saxon Cemetery at Finglesham, Kent-September/October 1964', mimeograph, Duckworth Laboratory, Cambridge, 1964.

- S. Jarman, 'Preliminary Report on the Skeletal Material from the Saxon Cemetery at Finglesham, Kent-September/October 1965', mimeograph, Duckworth Laboratory, Cambridge, 1966.

- R. B. Denston, 'The human remains', in Vera Evison, 'An Anglo-Saxon cemetery at Holborough, Kent', Arch. Cantia, 1956, 70: 112-113.

${ }^{7}$ H. W. Noble, 'Dental report', ibid., 113-117.

8 G. C. Dunning, 'The skeletal material', in S. E. Chadwick, 'The Anglo-Saxon cemetery at Finglesham, Kent: a reconsideration', Med. Arch., 1958, 11 : 60-63, appendix 1 


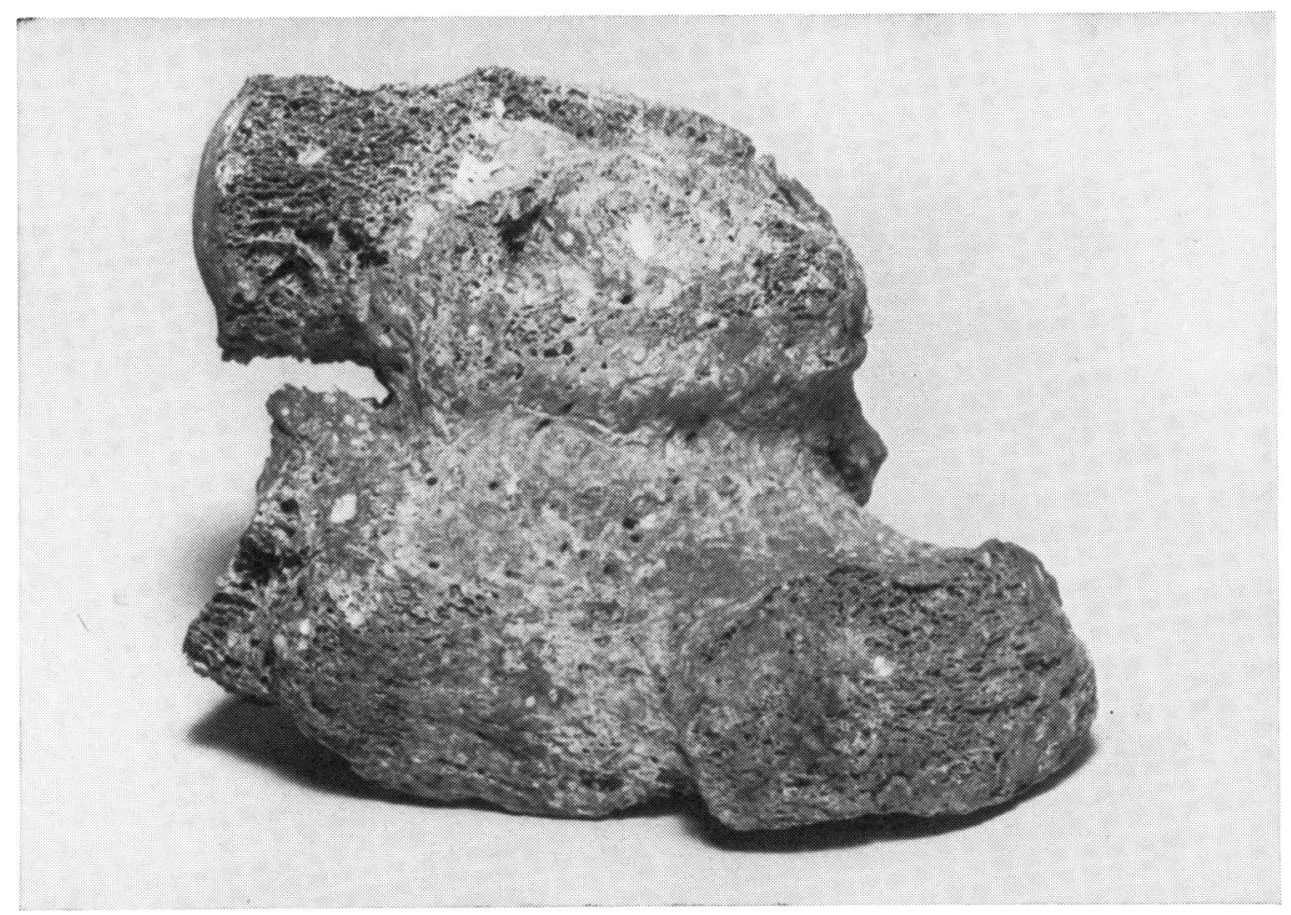

Figure 1

Inferior aspect of right calcaneus and talus, showing bridging. 


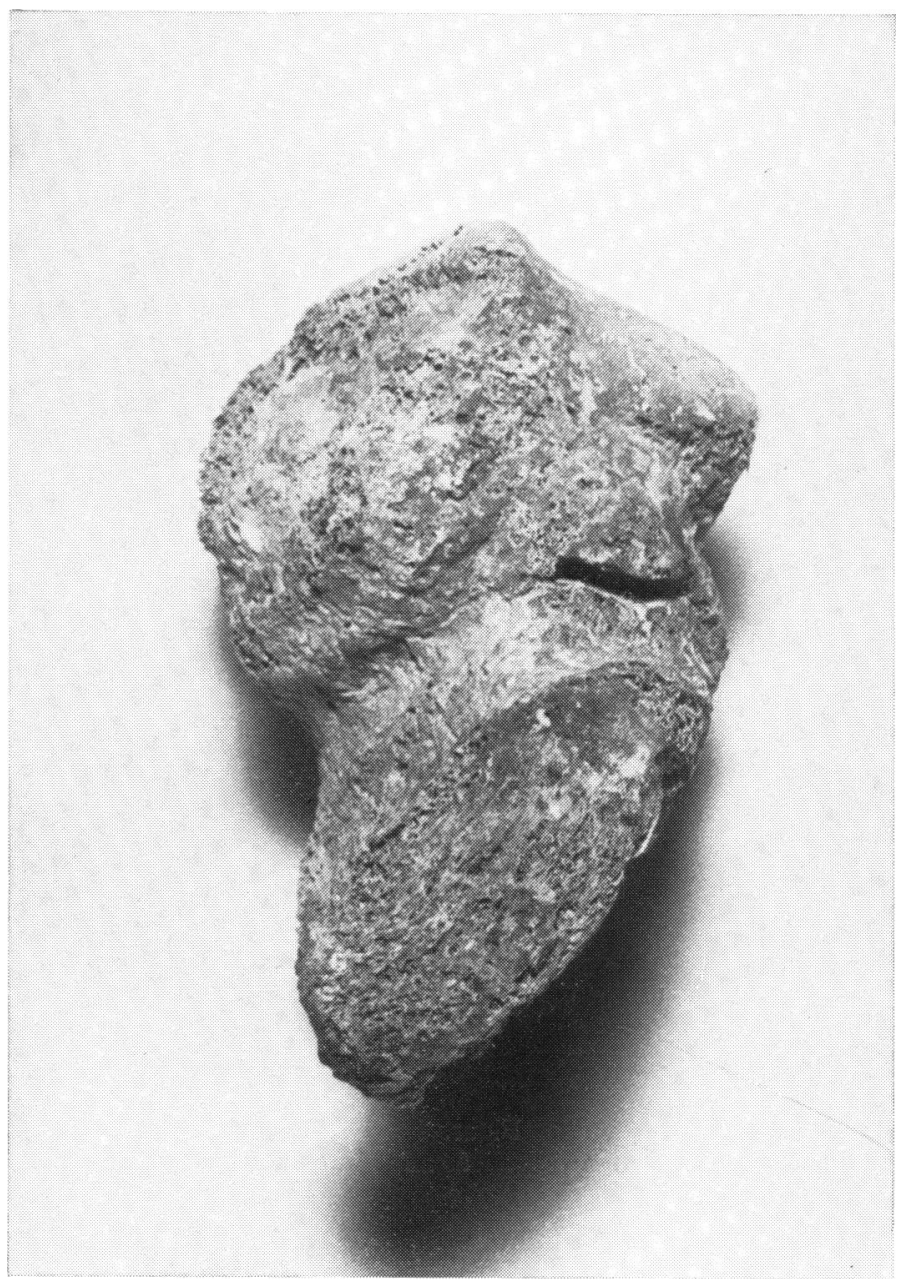

Figure 2

Posterior aspect demonstrating medial bridging and maintenance of joint space laterally. 


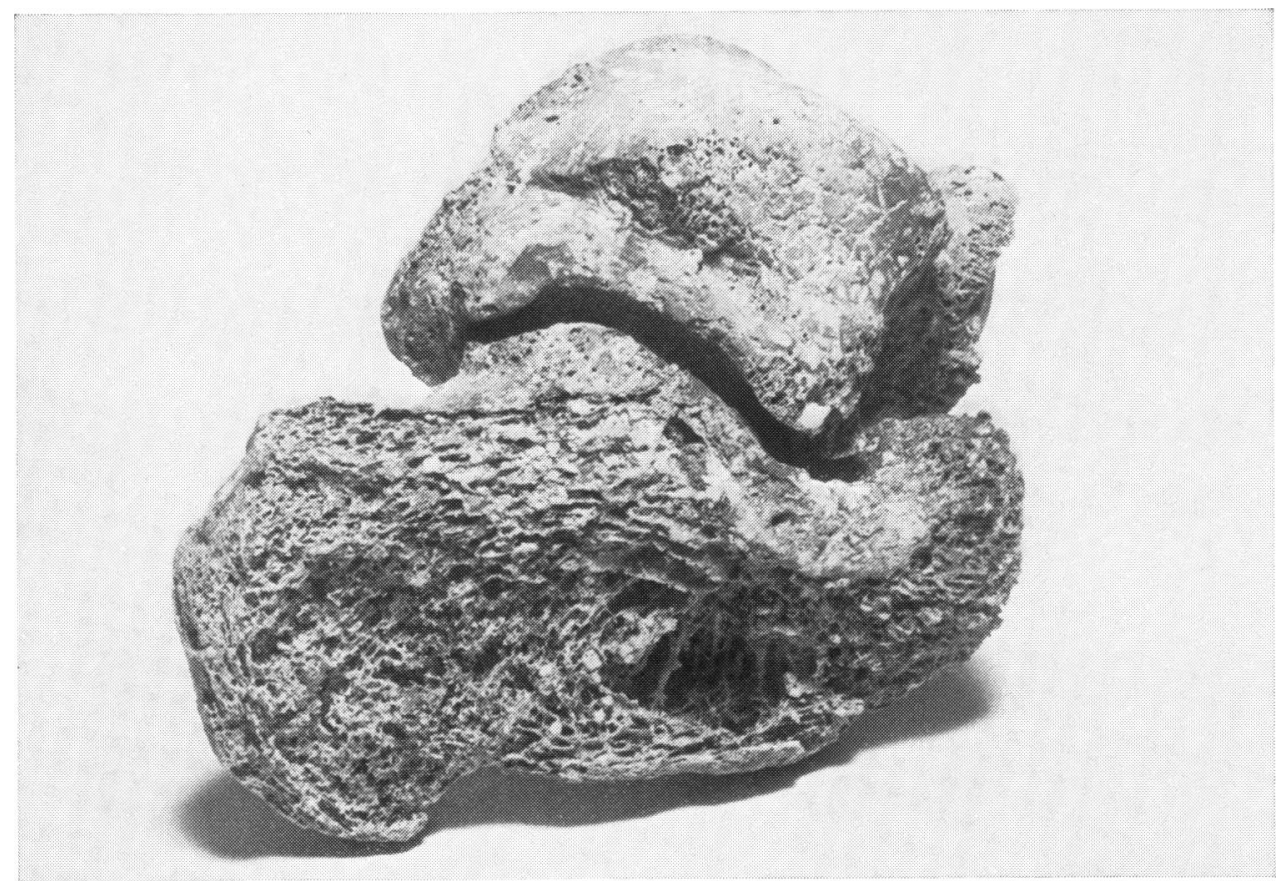

Figure 3

Lateral aspect illustrating maintenance of posterior joint space.

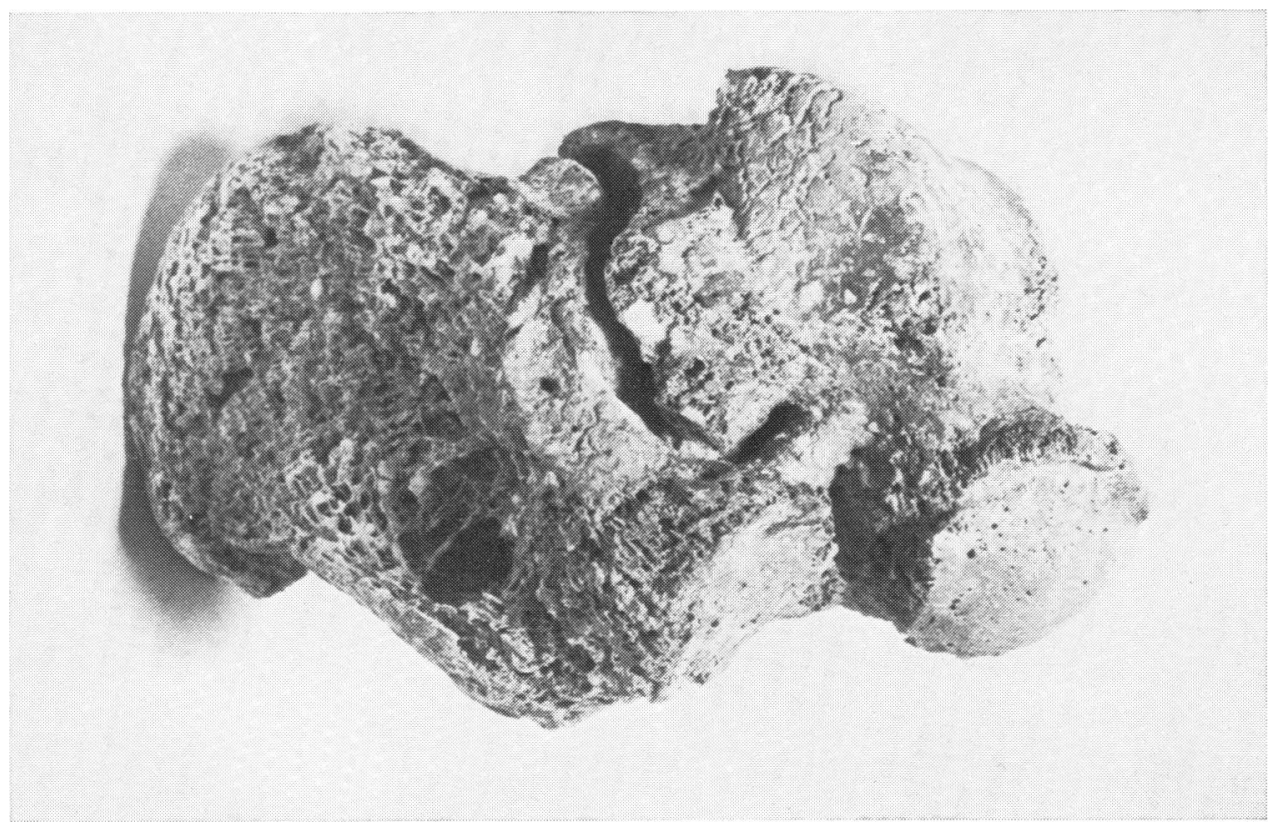

Figure 4

Antero-lateral aspect, the osteophyte on head of talus is shown. 


\section{Short Articles}

first complete set of foot bones and these included a pathologically deformed right heel.

\section{DESCRIPTION OF INDIVIDUAL}

Grave 12 contained the remains of a male of about forty years of age, with an in situ height of $175.5 \mathrm{~cm}$. His general appearance was muscular and he exhibited severe dental attrition and some vertebral osteoarthrosis. Several parts of the skeleton did not survive, notably the arms, shoulders, and ribs, and the remnants of vertebrae and pubic bones were very fragile. The survival of the lower limbs was probably a result of their having been placed on a slightly elevated, and therefore drier, plane than the remainder of the body.

\section{DESCRIPTION OF HEEL}

The specimen consists of an intact right talus and a virtually complete right calcaneus which is $8.0 \mathrm{~cm}$. long (heel to calcaneo-cuboid joint surface).

The medial aspects of both bones are fortunately in good condition and exhibit bony fusion of the anterior and middle talo-calcaneal joints (Fig. 1) which extends back to the postero-medial aspect of the posterior joint (Fig. 2), thus occluding the sinus tarsi. The fusion is solid and contains nutrient foramina. The posterior joint space is otherwise maintained and, though narrow, shows no evidence of osteoarthrosis (Fig. 3). The contour of the two bones is otherwise normal; in particular, there is no evidence of a healed fracture and the talo-tibial joint is normal. The talo-navicular joint surface, however, has an osteophyte projecting dorso-laterally (Fig. 4).

The left talus and calcaneus are normal.

\section{DISCUSSION}

Talo-calcaneal bridging is one of the two commonest forms of tarsal coalition-a term for fusion of various combinations of the tarsal bones produced by failure of differentiation of the primitive mesenchyme of the developing foot. The result is a complete or partial bridge of bone joining the talus and calcaneus, usually in the region of the sustentaculum tali, but occasionally occurring posteriorly.

The incidence in twentieth-century societies is not known for certain, but reported Caucasian series give incidences of under one per cent of the general population. ${ }^{9}$ Eighty per cent of cases are bilateral.

On the basis of a clinical and radiological study of patients and their first-degree relatives, Leonard ${ }^{9}$ considered tarsal coalition to be a genetic disorder, most probably inherited as an autosomal dominant of very nearly full penetrance. In his series forty-five per cent of probands' siblings, and thirty-four per cent of probands' parents were affected.

The talo-calcaneal bridge, if complete, results in loss of inversion and eversion of

- M. A. Leonard, 'The inheritance of tarsal coalition and its relationship to spastic flat foot', J. Bone Jt Surg., 1974, 56B: 520-526. 


\section{Short Articles}

the foot at the talo-calcaneal joint. Any inversion or eversion of the foot which occurs does so due to abnormal movements of other joints. Approximately fifty per cent of cases are symptomatic and it is these cases which constitute one of the main causes of the syndrome of "peroneal spastic flat foot". This is a condition that generally commences during adolescence, possibly because ossification of the cartilaginous anlage of the tarsal bridge reduces its resilience and throws abnormal stresses on adjacent joints. The abnormal movements at these joints result in pain and subsequent protective spasm of the peroneal muscles.

The Updown specimen exhibits a strongly associated feature; that of the osteophyte formation of the dorso-lateral surface of the head of the talus, which occurs as a result of abnormal movement at the talo-navicular joint. ${ }^{10,11}$

Talo-calcaneal bridging is well documented and has been recognized as an anatomical variant, rather than a pathological entity, since the time of John Hunter, ${ }^{12}$ in whose collection a bilateral example exists, probably from the eighteenth century. ${ }^{13}$ It was considered by Pfitzner in 1896 and Dwight in 1907 to be due to fusion of an accessary os sustentaculi with both the talus and the os calcis. ${ }^{14,15,16}$ However in 1955 Barbara Harris ${ }^{17}$ found complete talo-calcaneal bars in foetal feet, supporting the thesis that the lesion resulted from failure of the primitive mesenchyme to separate completely into individual tarsal bones. ${ }^{18}$

The clinical condition of peroneal spastic flat foot was described by Robert Jones in 1897. ${ }^{19,20}$ Despite the tentative suggestion of Holl in 1880 and the pioneering work of Slomann in 1922 and Badgley in 1927 on calcaneo-navicular bar and peroneal spasm, ${ }^{21}$ it was not until the work of Harris and Beath in 1948 that talo-calcaneal bridging became widely recognized as a major cause of peroneal spastic flat foot.

At the present time talo-calcaneal bridges often pass undetected as the bridge does not show on routine radiological views of the foot. Special standing axial views are required. 22,23

Several examples have survived from antiquity. Two early North American cases are known, both from pre-Columbian contexts, one belonging to a Mayan skeleton from Guatemala dates to about A.D. 850,24 and the other, which has bilateral talo-

${ }^{10}$ R. I. Harris, 'Retrospect-peroneal spastic flat foot', ibid., 1965, 47A: 1657-1667.

11 R. I. Harris, 'Rigid valgus foot due to talocalcaneal bridge', ibid., 1955, 37A: 169-183. 203.

12 R. I. Harris and T. Beath, 'John Hunter's specimen of talocalcaneal bridge', ibid., 1950, 32B:

${ }^{13}$ Leonard, op. cit., note 9 above.

14 R. I. Harris and T. Beath, 'Etiology of peroneal spastic flat foot', J. Bone Jt Surg., 1948, 30B: 624-634.

1s E. A. Jack, "Bone anomalies of the tarsus in relation to "peroneal spastic flat foot" ', ibid., 1954, 36: 530-542.

16 H. J. Seddon, 'Calcaneo-scaphoid coalition', Proc. Roy. Soc. Med., 1932, 26: 419-424.

17 Harris, op. cit., note 10 above.

18 Jack, op. cit., note 15 above.

10 Sir Robert Jones, 'The soldier's foot and the treatment of common deformities of the foot', Br. med. J., 1916, i: 709-711.

${ }^{20}$ Leonard, op. cit., note 9 above.

21 Ibid.

22 Harris, op. cit., note 10 above.

20 Harris and Beath, op. cit., note 14 above.

24 Harris, op. cit., note 10 above. 


\section{Short Articles}

calcaneal bridging, is from an Ohio Indian and is dated to A.D. 1000.25 A seventhto tenth-century site at Iona in Scotland has produced another case. ${ }^{26} \mathrm{~A}$ further bilateral specimen is lodged in the British Museum, Natural History, Kensington. This comes from a Dark Age cemetery in Cannington, Somerset, and is dateable to around A.D. 700. ${ }^{27}$ The Updown talo-calcaneal bridge, from a late sixth- to early seventh-century Anglo-Saxon context, predates this latter specimen by about one hundred years, and is therefore, the oldest surviving example reported in the literature.

\section{ACKNOWLEDGEMENTS}

We are indebted to Major A. James and his late wife Mary, of Updown Manor, for sponsorship of the excavation, and to Mrs. S. Hawkes, Director of the excavation, for access to archaeological information. Thanks are also due to Miss M. Pugh, Medical Photographer, Queen Mary's Hospital for Children, Carshalton, for the photographs; and we are grateful to the Consultant Surgeons of the St. George's Orthopaedic Rotation, London, for their helpful comments and suggestions.

${ }^{2}$ K. G. Heiple and C. O. Lovejoy, 'The antiquity of tarsal coalition', J. Bone Jt Surg., 1969, 51A: 979-983.

21 C. Wells, 'Fractures of the heel bones in early and prehistoric times', Practitioner, 1976, 217: 294-298.

17 R. Powers, Sub-Department of Anthropology, British Museum, Natural History, Kensington; personal communication. 